\title{
Analysis of the FGOALS Simulation on East Asian Westerly Jet in CMIP5 during the Meiyu Season
}

\author{
Yin Du and Zhiqing Xie
}

\begin{abstract}
Based on the Coupled Model Inter-comparison Project (CMIP5) coordinated experiments simulated by the IAP Flexible Global Ocean-Atmosphere-Land System Model (FGOALS), the properties of the East Asian Westerly Jet (EAWJ) during the Meiyu season have been investigated with the using statistical analysis, kinetic and thermodynamic methods. FGOALS can well capture the land and sea patterns of the EAWJ during the Meiyu period, which is that patterns of the EAWJ mainly core divided by the borderline of $120^{\circ} \mathrm{E}$. Comparison with the NCEP/NCAR reanalysis, the EAWJ simulated by the FGOALS model during the Meiyu period exists some biases, which are caused due to weaken of the simulated meridional temperature gradient at the middle and upper troposphere and decrease of the Tibetan Plateau heating, then lead to the corresponding south Asian high weaken. The position and intensity of the EAWJ in the early summer is closely associated with the spatial distribution and intensity of heavy precipitation in the middle and lower reaches of the Yangtze River. The position of the simulated EAWJ is obviously more northward and westward, and its intensity is greatly weaker, insulted that the Meiyu precipitation amount becomes less, especially in the lower reach of the Yangtze River.
\end{abstract}

Index Terms-East Asian westerly jet, South Asian high, meridional temperature gradient, coupling of the upper and lower level jets.

\section{INTRODUCTION}

The East Asia region is influenced by a complex distribution of land and sea and plateau terrain with the unique climate characteristics, and it is also one of the global sea-land-atmosphere interactions most complex area, or is one of the world's most typical monsoon region [1]. In the upper troposphere and lower stratosphere, there exists a narrow and strong westerly belt with large horizontal and vertical wind shears, which is referred to the East Asian Westerly Jet stream (EAWJ). The location and intensity of changes of the EAWJ is an important sign of the transition of atmospheric circulation, and its northward jump and southward shift is closely linked with prominent rainy season evolutions in East China and onset and end of the monsoon in East Asia [2]-[4]. On inter-annual and decadal time scales, the positional anomaly of the EAWJ is also associated with the floods and droughts over the East Asian Summer monsoon region [5]-[8]. Thus, the EAWJ plays an important

Manuscript received July 14, 2016; revised September 28, 2016. This work is supported by National Natural Science Foundation Grant 2015CB453200 and 41205063, Special Climate Change of China Meteorological Administration Grant CCSF201411 and Special developing projects of Key Forecasting Technology Grant CMAHX20160404.

Yin Du is with the KLME/ILCEC/CIC-FEMD/CDRC, NUIST, Nanjing, China (e-mail: duyinxie@163.com).

Zhiqing Xie is with the Jiangsu Climate Center, Jiangsu Meteorological Administration, Nanjing, China (e-mail: xiezhiqing9896@163.com). role in the East Asian weather and climate variation.

As well known, climate system models have become a powerful tool to simulate past and present climate and to project future climate. Therefore, it is necessary to use a climate system model to investigate the change of the EAWJ in the second half of $20^{\text {th }}$ century. With the latest version of the Institute of Atmospheric Physics (IAP) atmosphere-land-ocean coupled climate system model, the present of a new coordinated climate model experiment, known as CMIP5 (the fifth experiment of the Coupled Model Inter-comparison Project, which will be used for the Intergovernmental Panel on Climate Change (IPCC) fifth assessment report), have been proposed. Results are available to diagnose the principal characteristics of the EAWJ. A few numerical experiment studies indicate that the simulated wind field biases can affect the precipitation simulation in the East Asian monsoon region, and especially, the shift of the simulated EAWJ location and the bias of the westerly jet intensity are closely associated with the precipitation amount in Eastern China [9], [10]. Therefore, it is necessary to analyze and diagnose the model deficiencies in simulating the EAWJ for the improvement of climate model system.

In this study, we use the CMIP5 outputs from the IAP atmosphere-land-ocean coupled model to examine the simulation capabilities of the position and intensity of the EAWJ and its interannual variability, and to analysis the systematic bias and provide a scientific basis for the IAP coupled model improved in EAWJ simulation. In particular, this study highlights the June and July of the early summer rainy season (Meiyu) in East China because extremely heavy rainfall events frequently occur in center China during that period. It is noteworthy that the Meiyu season in the MLYR is the period from middle June to middle July in climate terms. In the following, the second section provides a description of the IAP coupled climate system model, the CMIP5 experimental designs and the datasets. Section III, IV, $\mathrm{V}$ and VI shows the results from the model's projections. The conclusions have given in the final section.

\section{Model ExPerimental Design, Data AND MethoD}

\section{A. Model Experimental Design}

The IAP climate system model used in this study is the second spectral version of the Flexible Global Ocean-Atmosphere-Land System model (FGOALS). This model provides state of the art computer simulations of the Earth's past, present and future climate states [11]. The atmospheric component is the Spectral Atmospheric Model of the IAP/State Key Laboratory of Numerical Modeling for Atmospheric Sciences and Geophysical Fluid Dynamics (LASG) (SAMIL). The horizontal resolution is $2.81^{\circ} \times 1.66^{\circ}$ 
with 26 hybrid vertical layers. The oceanic component is the LASG IAP Common Ocean Model (LICOM), and its resolution is $1^{\circ} \times 1^{\circ}$ with an increased resolution to $0.5^{\circ} \times 0.5^{\circ}$ in the tropical regions. The other components, including land surface, ice, and coupler components, are from the NCAR Community Climate System Model (CCSM) [12].

To investigate the major variability of the EAWJ, the results from three groups of CMIP5 coordinated experiments with FGOALS have been taken. The historical simulations have been integrated from 1850 to 2005. The imposed changing conditions of the historical simulations include atmospheric composition (including $\mathrm{CO}_{2}$ ) due to anthropogenic and volcanic influences, solar forcing, and concentrations of short-lived species and natural and anthropogenic aerosols. These experiments are all standard runs based on the CMIP5 experimental design [13]. To reduce the uncertainties arising from differing initial conditions, the historical simulations have three individual ensemble members, which are achieved with the different initial conditions derived from the pre-industry experiment. The follow evaluations and diagnoses were retrieved from these three ensemble methods. For a convenient comparison with observations, the FGOALS data with a horizontal resolution of longitude/latitude are interpolated on the grid points of the observed data by using a bilinear interpolation method.

\section{B. Data}

The observed datasets used to evaluate the model include the reanalysis circulation fields (such as the monthly-mean winds, geopotential height, and temperature, and so on) from the National Centers for Environmental Prediction and National Center for Atmospheric Research (NCEP/NCAR) for 1960-2005 [14]. The precipitation data analyzed here include the Global Precipitation Climatology Project (GPCP) [15]. Although the simulated period is $1850-2005$, our analysis is focused mainly on the Meiyu period from 1960 to 2005. The NCEP/NCAR reanalysis data are relatively reliable.

\section{Methods}

A local $\mathrm{t}$ test is applied to examine the statistical significance of the composite differences, and its formula is

$$
t=(\bar{x}-\bar{y}) /\left(S\left(\frac{1}{m_{1}}+\frac{1}{m_{2}}\right)^{1 / 2}\right)
$$

where $S^{2}=\left(\frac{m_{1}-1}{m_{1}} \sum_{i=1}^{m_{1}}\left(x_{i}-\bar{x}\right)^{2}+\frac{m_{2}-1}{m_{2}} \sum_{i=1}^{m_{2}}\left(y_{i}-\bar{y}\right)^{2}\right) /$ $\left(m_{1}+m_{2}-2\right), \mathrm{m}_{1}$ and $\mathrm{m}_{2}$ are the sample numbers for the positive and negative cases, and $\overline{\mathrm{x}}$ and $\overline{\mathrm{y}}$ are the means for the positive and negative cases, respectively.

The ageostrophic wind equation is:

$$
\mathbf{V}_{\mathrm{a}}=\frac{1}{\mathrm{f}} \mathbf{k} \times\left(\frac{\partial \mathbf{V}_{\mathrm{g}}}{\partial \mathrm{x}}+\mathbf{V}_{\mathrm{g}} \cdot \nabla \mathbf{V}_{\mathrm{g}}\right)
$$

where $\mathbf{V}_{\mathrm{a}}$ and $\mathbf{V}_{\mathrm{g}}$ are the ageostrophic and geostrophic winds, $\mathrm{f}$ is the Coriolis parameter, respectively. The parameter $\mathbf{V}_{\mathrm{a}}$, which points to the anticyclone (high pressure) of the westerly jet, is generated by $\frac{\partial \mathbf{v}_{\mathrm{g}}}{\partial \mathrm{x}}$.

\section{Climatology of the EAWJ}

\section{A. Horizontal Structure}

In this section, we analyze the FGOALS simulated climatological features of the EAWJ during the Meiyu period in the middle and lower reaches of Yangtze River (referred to MLYR) from 1960 to 2005, including the horizontal and vertical structure. We first examine the horizontal features of upper-tropospheric zonal wind. Fig. 1b shows the climatological mean (1960-2005 average) of simulated 200-hPa zonal wind during the Meiyu period in the MLYR. The strong westerly is located at $35^{\circ} \mathrm{N}-55^{\circ} \mathrm{N}$ in the middle latitude, with two stronger centers located north of $40^{\circ} \mathrm{N}$ over the Eurasia and west Pacific, and their values greater than 20 $\mathrm{m} \mathrm{s}^{-1}$. Based on the different between NCEP/NCAR reanalysis and FGOALS, there exist significantly positive values in the middle and lower latitudes and remarkably negative one in the high latitude, especially in Eurasia continent (seen in Fig. 1c). Therefore, the spatial feature in FGOALS is consistent with that shown in the NCEP/NCAR reanalysis. But, the simulated EAWJ position is significantly northerly than the observed one and its intensity is obviously weaker.
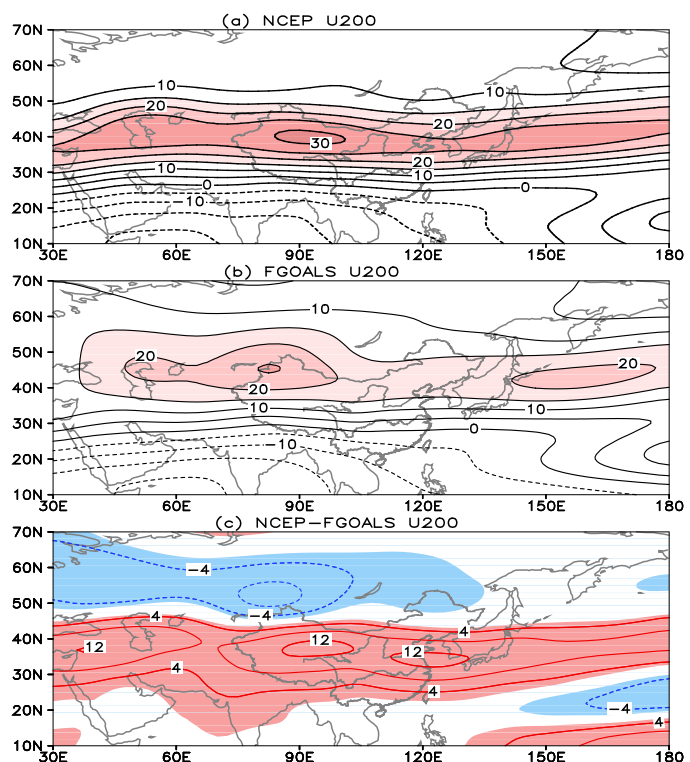

Fig. 1. The climatology ( $\mathrm{a}, \mathrm{b}$; shaded: $\mathrm{u} \geq 15 \mathrm{~m} \mathrm{~s}^{-1}$ ) and its corresponding difference (c; shaded: $95 \%$ significant confidence) of the $200 \mathrm{hPa}$ zonal wind $\left(\mathrm{m} \mathrm{s}^{-1}\right)$ during the Meiyu period from 1960 and 2005.

\section{B. Vertical Structure}

In order to study the east-west change of the EAWJ during the period of Meiyu in the MLYR, so we choose the region of $30^{\circ} \mathrm{N}-55^{\circ} \mathrm{N}$, where the observed and simulated EAWJs generally appear. Fig. 2 presents longitude-height cross sections of the zonal wind averaged $30^{\circ} \mathrm{N}-55^{\circ} \mathrm{N}$ in NCEP/NCAR reanalysis, FGOALS and their different, respectively. During the Meiyu period, the core of the EAWJ is located at the upper troposphere, with the two strong central value of $18 \mathrm{~m} \mathrm{~s}^{-1}$ near $55^{\circ} \mathrm{E}$ and $90^{\circ} \mathrm{E}$, and the latter is stronger than the former. The simulated zonal wind structure is similar to the observed, but the strongest zonal wind value is greater than $15 \mathrm{~m} \mathrm{~s}^{-1}$ located west of $90^{\circ} \mathrm{E}$. There are significantly positive values in the middle and upper troposphere. The height position of the EAWJ simulated by the FGOALS model are in good agreement with the NCEP/NCAR reanalysis, but the longitude position of the 
simulated EAWJ is different with the observed, especially westward in the east Asian continent. In addition, the intensity of the simulated EAWJ is obvious weaker than that of the observed one.
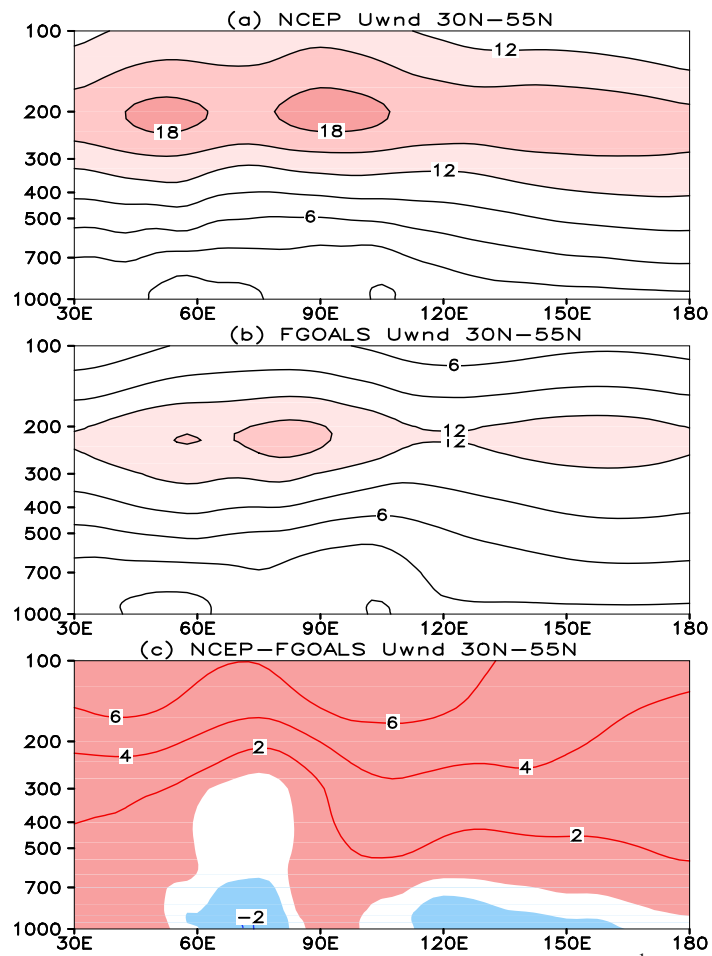

Fig. 2. Longitude-height cross sections of zonal wind in $\mathrm{m} \mathrm{s}^{-1}$ averaged $30^{\circ} \mathrm{N}-55^{\circ} \mathrm{N}$ during the Meiyu period. Shading is greater than $12 \mathrm{~m} \mathrm{~s}^{-1}$ in $(\mathrm{a}-\mathrm{b})$ and $95 \%$ significant confidence in (c).
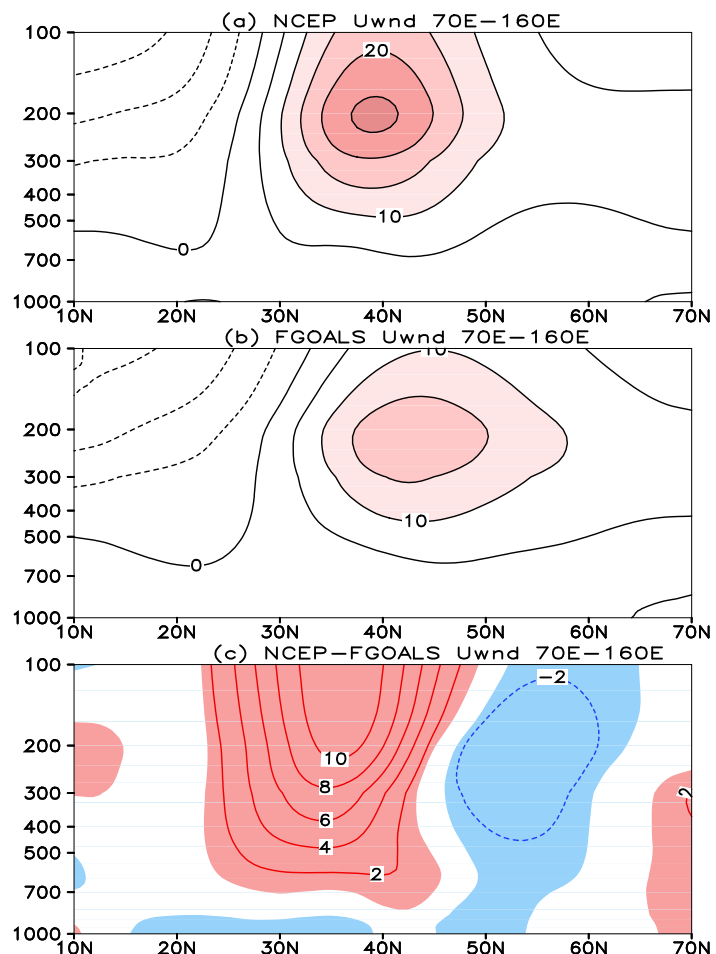

Fig. 3. Latitude-height (pressure) cross sections of zonal wind in $\mathrm{m} \mathrm{s}^{-1}$ averaged $70^{\circ} \mathrm{E}-160^{\circ} \mathrm{E}$ during the Meiyu period. Contour interval is $5 \mathrm{~m} \mathrm{~s}^{-1}$ in (a-b), and $2 \mathrm{~m} \mathrm{~s}^{-1}$ in (c), respectively, and its corresponding shading is greater than $10 \mathrm{~m} \mathrm{~s}^{-1}$, and $95 \%$ significant confidence.

How does the south-north position of the simulated EAWJ change? Fig. 3 shows latitude-height (pressure) cross section of the simulated zonal wind averaged $70^{\circ} \mathrm{E}-160^{\circ} \mathrm{E}$. The westerly jet core is located at the upper troposphere of
$300-200 \mathrm{hPa}$, with the central value of $15 \mathrm{~m} \mathrm{~s}^{-1}$ north of $40^{\circ} \mathrm{N}$, and gradually becomes weaker southward and northward, especially in lower latitude. In NCEP/NCAR reanalysis, the strong westerly appears the upper troposphere in the middle latitude, with the central value of $25 \mathrm{~m} \mathrm{~s}^{-1}$ near $40^{\circ} \mathrm{N}$ at $200 \mathrm{hPa}$. There are significantly positive different in the middle latitude and significantly negative one in the high latitude, especially the upper troposphere in the middle latitude (Fig. 3c). So, the locations (height and latitude) of the westerly jet stream simulated by FGOALS are in good agreement with the NCEP/NCAR reanalysis, but the simulated westerly jet core is more obviously north than the observed one.

\section{INTERANNUAL CHARACTERISTICS OF THE EAWJ}

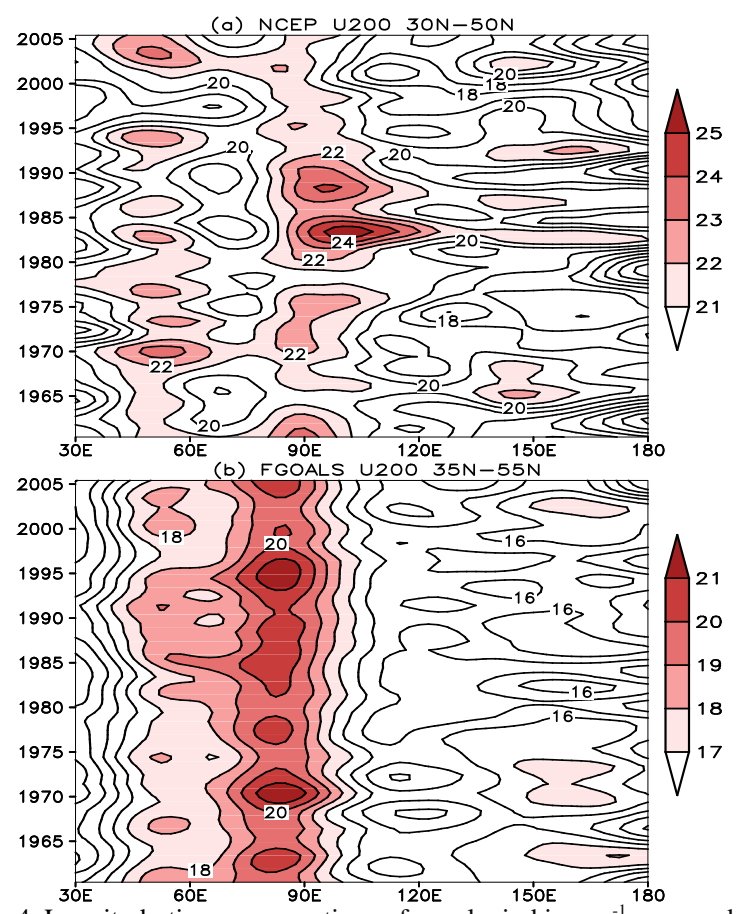

Fig. 4. Longitude-time cross sections of zonal wind in $\mathrm{m} \mathrm{s}^{-1}$ averaged (a; shaded: $\mathrm{u} \geq 21$ ) $30^{\circ} \mathrm{N}-50^{\circ} \mathrm{N}$ in observation and (b; shaded: $\mathrm{u} \geq 17$ ) $35^{\circ} \mathrm{N}-55^{\circ} \mathrm{N}$ in simulation, respectively.

Based on the previous analysis of the horizontal and vertical structures of the simulated EAWJ during the period of Meiyu in the MLYR, we know that the FGOALS can better capture the mainly climatologic features of the EAWJ, including the spatial distribution, position and intensity. Then, we will pay more attention on the interannual variability of the EAWJ, which directly infect the weather and climate in the MLYR. Fig. 4 illustrates the longitude-time cross sections of $200-\mathrm{hPa}$ zonal wind averaged $35^{\circ}-55^{\circ} \mathrm{N}$, which represent the interannual changes of the EAWJ core east-west displacements. During the Meiyu period, there are two main features of the EAWJ in the NCEP/NCAR reanalysis. First main feature is that there are two jet centers in the East Asia, one is located over the East Asian continent near $90^{\circ} \mathrm{E}$, and the other over the west pacific near $150^{\circ}$ E. Second main feature is that the westerly jet stream located over north of Tibetan Plateau appears shift remarkably westward and its intensity gradually weakens after 1980 . The simulated strong westerly cores are three and the strongest one is in the middle, but the EAWJ position and change is obvious different with 
the observed, especially that over the Tibetan Plateau, where the westerly jet stream is stably located at west of $90^{\circ} \mathrm{E}$ and no trend change (Fig. 4b).
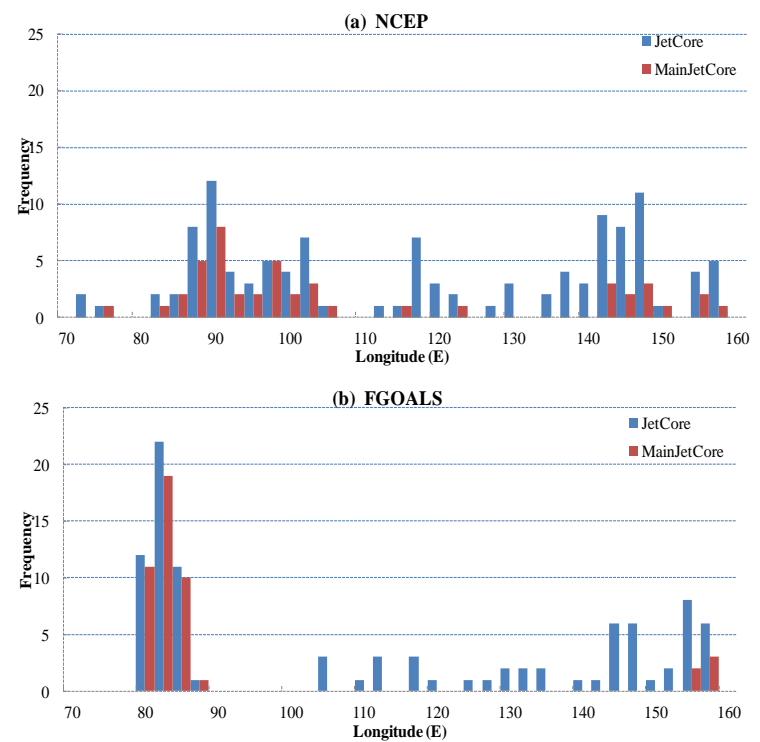

Fig. 5. The occurrence frequencies of the westerly jet core (blue) and mainly core (red) in $\left(20^{\circ}-60^{\circ} \mathrm{N}, 70^{\circ} \mathrm{E}-160^{\circ} \mathrm{E}\right)$ during the period of Meiyu.

To order to further valid the result that the strongest center of the EAWJ oscillates over the East Asian continent and the west Pacific during the period of Meiyu. We choose the region of $70^{\circ} \mathrm{E}-160^{\circ} \mathrm{E}, 20^{\circ} \mathrm{N}-60^{\circ} \mathrm{N}$ to calculate the occurrence frequencies of the westerly west jet center and its strongest one. Fig. 5 shows the occurrence frequencies of the EAWJ core. The result is found that the majority strongest centers of the simulated EAWJ focus on the East Asian continent at $80^{\circ} \mathrm{E}-90^{\circ} \mathrm{E}$ and the very small part one over the west Pacific at $155^{\circ} \mathrm{E}-160^{\circ} \mathrm{E}$. However, the strongest centers of the observed EAWJ locate mainly two regions of $82^{\circ} \mathrm{E}-108^{\circ} \mathrm{E}$ and $142^{\circ} \mathrm{E}-160^{\circ} \mathrm{E}$, and the form is obvious more than the latter. The borderline of $120^{\circ} \mathrm{E}$ can divide the EAWJ into sea and land patterns during the Meiyu period of 1960-2005.

\section{PRECIPITATION}

Based on the pervious analysis, the FGOALS model can better captures the main characteristics of the EAWJ, including its position, intensity and interannual variability, but the simulated EAWJ position is remarkable more northward and westward than the observed one and its intensity is also greater weak. During the Meiyu period, more or less precipitation accounts in the MLYR can bring tremendous damages to the property and life of local people. The mean total precipitation amounts of Meiyu are given in Fig. 6. The observed heavy precipitation occurs in the MLYR and south China and the rainfall amount is more than $7 \mathrm{~mm}$ day $^{-1}$ as in Fig. 6a. While the simulated precipitation is obviously weaker in the MLYR, especially in the lower reach of the Yangtze River and the rainfall amount is less than 5 $\mathrm{mm}$ day $^{-1}$. Therefore, the position of intensity of the EAWJ during the Meiyu period can influences the spatial distribution and intensity of heavy precipitation in the MLYR Why the simulated EAWJ during the Meiyu period is obviously weak?
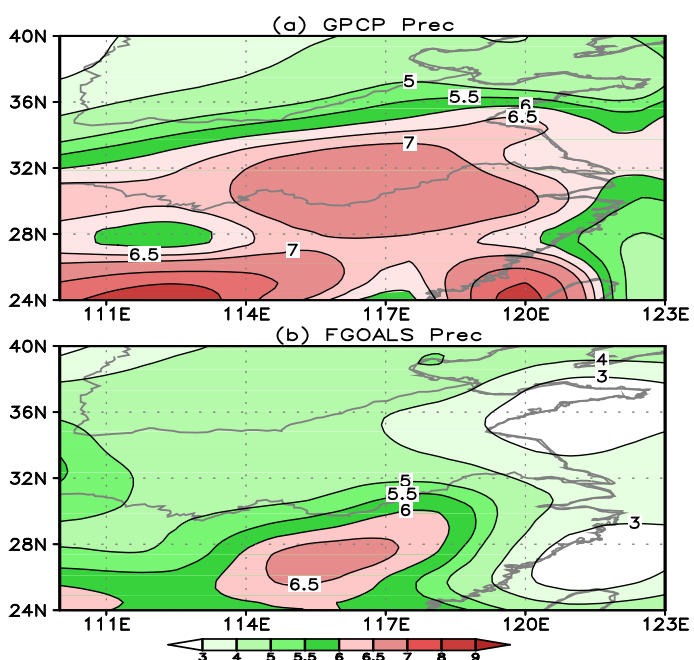

Fig. 6. Horizontal distribution of mean precipitation (shaded $\geq 2.5 \mathrm{~mm} \mathrm{day}^{-1}$ ) in GPCP (a) and FGOALS (b) during the period of Meiyu.

\section{Possible MECHANISM}

\section{A. Principle of Thermal Wind}

Based on the principle of thermal wind, the vertical shear of zonal wind is proportional to the meridional temperature gradient (hereinafter MTG) averaged between the two pressure levels. In other words, a strengthened vertical shear corresponds to an enhanced MTG.

Fig. 7 shows the horizontal distribution of the mean air temperature between 500 and $200 \mathrm{hPa}$ and its corresponding MTG. In NCEP/NCAR reanalysis, there exist two MTG belts at the middle and upper troposphere, one is positive and located over the region of $30^{\circ} \mathrm{N}-55^{\circ} \mathrm{N}$ in the middle latitude and its center located near $40^{\circ} \mathrm{N}$ and its value is greater than $3 \mathrm{~K}\left(5^{\circ} \mathrm{Lat}\right)^{-1}$; the other is negative and located over the region of $10^{\circ} \mathrm{N}-20^{\circ} \mathrm{N}$ in the lower latitude and its value is more than $1 \mathrm{~K}\left(5^{\circ} \mathrm{Lat}\right)^{-1}$ in Fig. $7 \mathrm{a}$. Therefore, the former is greatly stronger than the latter. The warming center is located over the Indian peninsula and Tibet Plateau and its value is greater than $250 \mathrm{~K}$. The simulated MTG and its corresponding mean temperature is similar distribution to the observed one, but its intensity is more than $248 \mathrm{k}$ and significantly apparent weaker than the observed one in the lower and high latitudes including the south China, only warmer over the north China in the middle latitude. This suggests that as an important heat resource to heat the upper atmosphere, the Tibetan Plateau heating effect during the Meiyu period becomes weak. The large MTG at the middle and upper troposphere matches well with the $200-\mathrm{hPa}$ westerly jet, thus the $200 \mathrm{hPa}$ westerly jet always follows the larger MTG. The MTG weakens over East Asia, and the EASWJ intensity reduces. Thus, the MTG change determines indirectly the shift of the core position and intensity variable of the EASWJ.

The next question is that on the interannual scale, why the simulated EAWJ center during the Meiyu period is stead located over the region of $80^{\circ} \mathrm{N}-90^{\circ} \mathrm{N}$. Fig. 8 shows the longitude-time cross-sections of the mean MTG between 500 to $200 \mathrm{hPa}$ averaged $37^{\circ} \mathrm{N}-43^{\circ} \mathrm{N}$ in observation and $42^{\circ} \mathrm{N}-48^{\circ} \mathrm{N}$ in simulation, respectively. The simulated strongest MTG center appears steadily over the regions of $70^{\circ} \mathrm{E}-90^{\circ} \mathrm{E}$, especially the strongest MTG center on the right areas, which match well the simulated EAWJ center location 
in Fig. 4b. The observed MTG have three strong cores located over near $40^{\circ} \mathrm{E}, 90^{\circ} \mathrm{E}$ and $140^{\circ} \mathrm{E}$, respectively, and the center one is great strongest and have obvious shit westward after 1980, which is same as the EAWJ (Fig. 4a). Based on the previous analysis, the obvious feature is that there is a good correspondence between the strong MTG and EAWJ, that is, the EAWJ center always follows larger MTG. Therefore, the heat field in the lower and middle troposphere indirectly influences the temperature structure, and results in the change of the MTG and the pressure field, then leading to the wind field adjustment and the EAWJ variation.

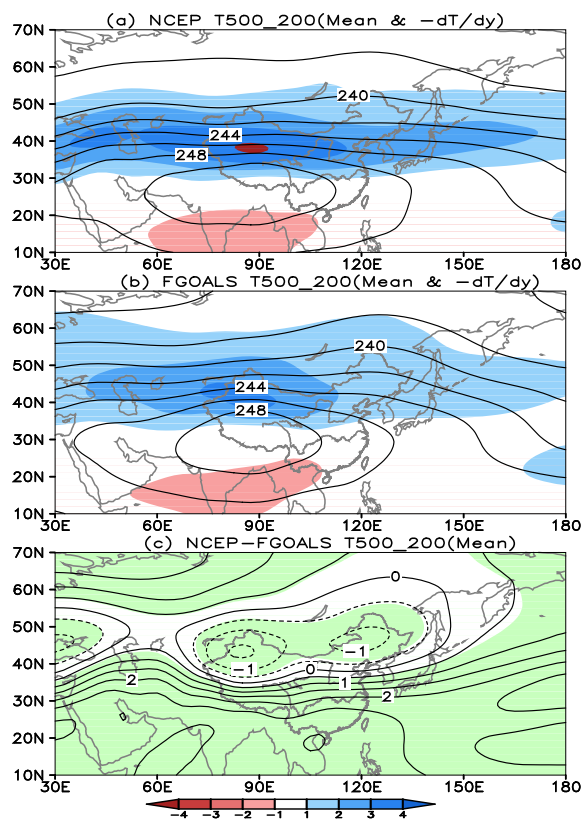

Fig. 7. Horizontal distribution of mean atmospheric temperature between $500 \mathrm{hPa}$ and $200 \mathrm{hPa}$ (contour; unit: $\mathrm{K}$ ) and its corresponding meridional temperature gradient (MTG) during the Meiyu. Shaded regions is greater than $\left.1 \mathrm{~K}\left(5^{\circ} \mathrm{Lat}\right)^{-1}\right)$ in $(\mathrm{a}-\mathrm{b})$ and $95 \%$ significant confidence in (c), respectively.

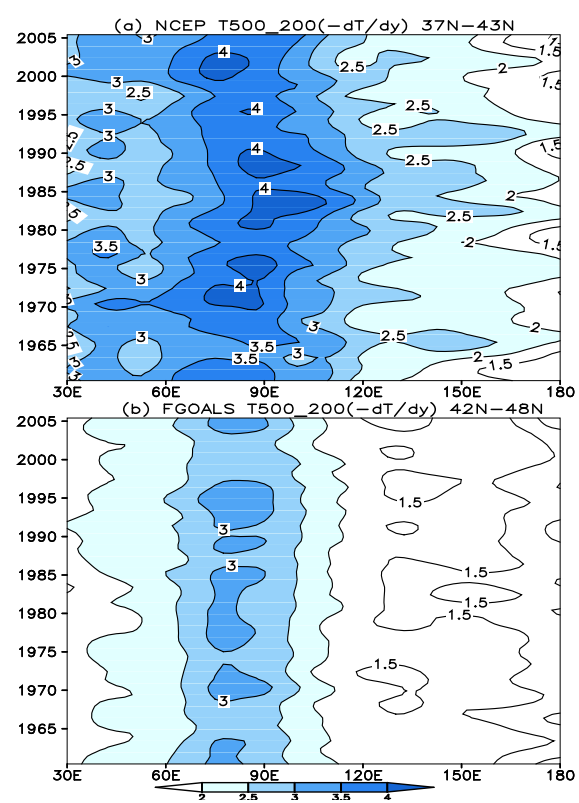

Fig. 8. Longitude-time cross-sections of mean MTG (Unit: K $\left.\left(5^{\circ} \text { Lat }\right)^{-1}\right)$ between $500 \mathrm{hPa}$ and $200 \mathrm{hPa}$ averaged (a) $37^{\circ}-43^{\circ} \mathrm{N}$ in observation and (b) $42^{\circ}-48^{\circ} \mathrm{N}$ in simulation, respectively.

\section{B. South Asian High}

The south Asian high (SAH) is a thermal high pressure system, whose intensity depends on the distribution of heterogeneous diabatic heating over the Tibetan Plateau and the Asian summer monsoon area. Its variation in warm season also depends strongly on changes in atmospheric heating, especially the thermal effect of the Tibetan Plateau [16]. Fig. 9 indicates the spatial distribution of mean 100-hPa potential height in NCEP/NCAR reanalysis and FGOALS, respectively. When the atmosphere air at the middle and upper troposphere is warmer, the observed $\mathrm{SAH}$ is great strong, and its center is located southward near $30^{\circ} \mathrm{N}$ and its value is greater than $16800 \mathrm{~m}$. When the atmosphere air at the middle and upper troposphere is cooler, the simulated SAH is great weak, and its center is northward near $35^{\circ} \mathrm{N}$ and its value is more than $16720 \mathrm{~m}$. In general, the strong SAH is on the north of the strong westerly jet and on the south of the strong easterly jet. Thus, the simulated weak SAH is accompanied with the weak westerly jet.
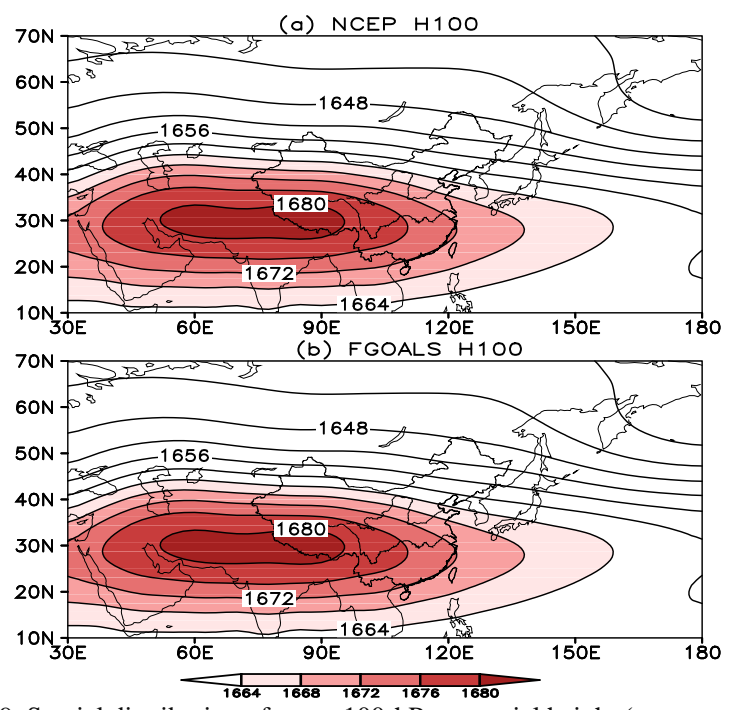

Fig. 9. Spatial distribution of mean 100-hPa potential height (contour; unit: $10 \mathrm{~m}$ ) in NCEP/NCAR reanalysis (top panel) and FGOALS (down panel), respectively. Shading is greater than 1668 .

\section{Coupling of the Upper and Lower Jets}

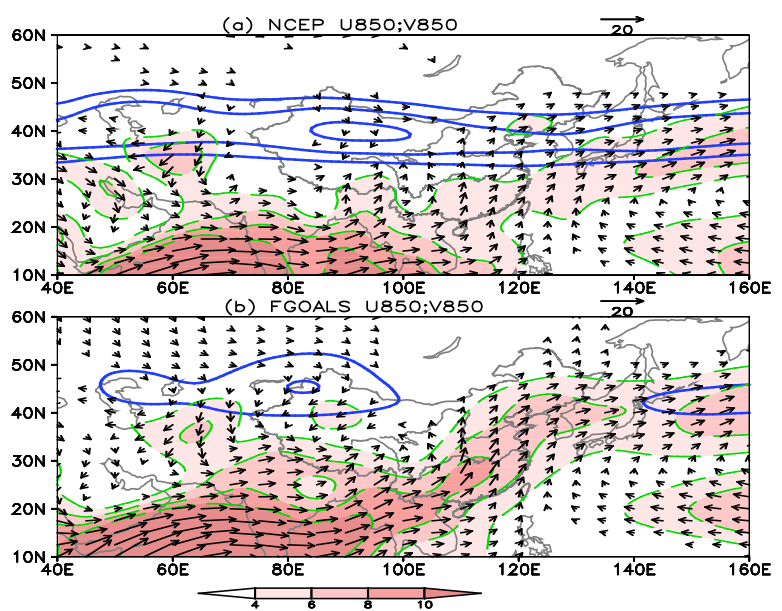

Fig. 10. Spatial distribution of the 850-hPa wind (vector, unit: $\mathrm{m} \mathrm{s}^{-1}$ ) for NCEP/NCAR reanalysis (a) and FGOALS (b), respectively. The solid (dash) lines denote the 200-hPa upper-level (850-hPa lower-level) jet.

The entrance of the westerly jet has anomalously south ageostrophic wind. A circulation is formed in the $y-z$ coordinates, which, together with the direct circulation generated by the earth rotation, causes the convergence and upward motion to strengthen in the entrance of the westerly 
jet. If the water vapor is sufficient, strong convection will happen and heavy precipitation will appear in this region. Therefore, the ageostrophic wind south of the westerly jet entrance is conducive to the occurrence of heavy precipitation.

Fig. 10 demonstrates the spatial distributions of the upperand lower- level jets with the observation and simulation. The MLYR is just located on the north of the observed lower-level southwest jet and the south of the upper-lever westerly jet and the entrance of the EAWJ center over the west pacific, which is good corresponding to the heavy precipitation. However, the simulated southwest lower-level jet during the Meiyu season reaches on north of China and extends eastward from Korean peninsula, passed center of Japan to the northwest pacific, not coupling with the upper westerly jet. At the same time, the MLYR is only the water vapor transport channel.

\section{CONCLUSION AND DISCUSSION}

Based on the 46-yr FGOALS and NCEP/NCAR reanalysis data from 1960 to 2005, we investigate the dominant characteristics of the EAWJ during the Meiyu period. Comprehension of the previous analysis, the FGOALS model can better seize the mainly characteristics of the EAWJ during the Meiyu period, including the spatial distribution, intensity and position and its interannual variability. During the Meiyu period, the obvious feature of the EAWJ strong core exists two patterns of the land and sea ones divided by the borderline of $120^{\circ} \mathrm{E}$ in the middle latitude. However, compared with the NCEP/NCAR reanalysis, the simulation of the EAWJ in the FGOALS model has some obvious biases. That is, the simulated EAWJ intensity during the Meiyu period is remarkable weaker, its location is notable northward and westward, and its interannual change is weaker, especially over the East Asian continent.

In general, the obvious feature is that there is a good correspondence between the MTG and EAWJ through the thermal wind balance, and EAWJ center always follows larger MTG during the Meiyu period. In fact, the simulated MTG at the middle and upper troposphere is evidently weaker than the observed one during the Meiyu period, and its position is also distinctly more northward and westward, which are closely associated with the weaken of the EAWJ and its location northward and westward. The simulated air temperature at the middle and upper troposphere is colder in the lower latitude and warmer in the middle latitude, which is caused by the diabatic heating weaken, including the sensible heating and latent heating, especially over the Tibetan plateau, leading to the SAH decrease. This suggests that the Tibetan plateau in the coupled model plays an important role in heat resource exchange during the Meiyu period.

The position and intensity of the EAWJ in the early summer is closely associated with the spatial distribution and intensity of heavy precipitation in the MLYR. The intensity of the simulated EAWJ is greatly weaker, insulted that the Meiyu precipitation amount becomes less, especially in the lower reach of the Yangtze River. In the FGOALS model, there don't exist the coupling of the upper- and lower- level jets in the MLYR, where the water vapor convergence and strong vertical motion is poor, then the heavy precipitation less occurs here.

\section{REFERENCES}

[1] R. C. Yu, B. Wang, and T. J. Zhou, "Tropospheric cooling and summer monsoon weakening trend over East Asia," Geophys. Res. Lett., vol. 31, L22212, 2004

[2] S. L. Xuan, Q. Y. Zhang, and S. Q. Sun, "Anomalous midsummer rainfall in Yangtze River-Huaihe River valleys and its association with the East Asia westerly jet," Adv. Atmos. Sci., vol. 25, pp. 387-397, 2011.

[3] Z. Q. Xie, Y. Du, and S. Yang, "Zonal extension and retraction of the subtropical westerly jet stream and evolution of precipitation over East Asia and the Western Pacific," J. Climate, vol. 28, pp. 6783-6798, 2015.

[4] Y. C. Zhang, X. Y. Kuang, W. D. Guo, and T. J. Zhou, "Seasonal evolution of the upper-troposphere westerly jet core over East Asia,' Geophys. Res. Lett., vol. 33, L11708, 2006.

[5] T. Sampe and S. P. Xie, "Large-scale dynamics of the Meiyu-Baiu rainband: Environmental forcing by the westerly Jet," J. Climate, vol. 23, pp. 113-134, 2010.

[6] R. Y. Lu, H. Ye, and J. G. Jhun, "Weakening of interannual variability in the summer East Asian upper-tropospheric westerly jet since the mid-1990s," Adv. Atmos. Sci., vol. 28, pp. 1246-1258, 2011.

[7] Y Du, T. Li, Z. Q. Xie, and Z. W. Zhu, " Interannual variability of the Asian subtropical westerly jetin boreal summer and associated with circulation and SST anomalies," Climate Dyn., vol. 46, pp. 2673-2688 2016.

[8] X. J. Ren, X. Q. Yang, T. J. Zhou, and J. P. Huang, "Diagnostic comparison of the East Asian subtropical jet and polar-front jet: Large-scale characteristics and transient eddy activities," Acta Meteor Sinica, vol. 68, pp. 1-11, 2010.

[9] Q. Ding, B. Wang, and J. M. Wallace et al., "Tropical-extratropical teleconnections in boreal summer: Observed interannual variability," $J$. Climate, vol. 24, pp. 1878-1896, 2011.

[10] Y. C. Zhang and L. L. Guo, "Relationship between the simulated East Asian westerly jet biases and seasonal evolution of rainbelt over eastern China," Chinese Science Bulletin, vol. 50, pp. 1503-1508, 2005.

[11] Q. Bao, G. X. Wu, and Y. M. Liu, "An introduction to the coupled model FGOALS1.1-s and its performance in East Asia," Adv. Atmos. Sci., vol. 27, pp. 1131-1142, 2010

[12] J. T. Kiehl and P. R. Gent, "The community climate system model, version 2," J. Climate, vol. 17, 3666-3682, 2004.

[13] K. E. Taylor, R. J. Stouffer, and G. A. Meehl, “A summary of the cmip5 experiment design," pp. 1-33, 2009

[14] E. Kalnay, M. Kanamitsu, and R. Kistler, "The NCEP/NCAR 40-year reanalysis project," Bull. Amer. Meteor. Soc., vol. 77, pp. 437-471, 1996.

[15] P. P. Xie, J. E. Janowiak, and P. A. Arkin, "GPCP pentad precipitation analyses: An experimental dataset based on gauge observations and satellite estimates,"J. Climate, vol.16, pp. 2197-2214, 2003.

[16] X. J. Ren, D. J. Yang, and X. Q. Yang, "Characteristics and mechanisms of the subseasonal eastward extension of the South Asian high," J. Climate, vol. 28, pp. 6799-6822, 2015.

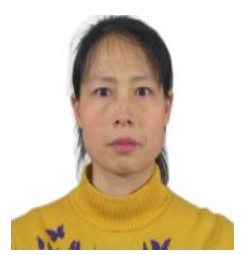

Du Yin is a lecturer at the School of Atmospheric Sciences, Nanjing University of Information Science and Technology (NUIST). She received her bachelor of science degree in meteorology from Nanjing Institute of Meteorology in 2002 and her master's and $\mathrm{PhD}$ degrees in climatology from Nanjing University and graduated in 2009. Her research interests are in

regional climate change diagnosis and numerical simulation, especially in East Asian climate.

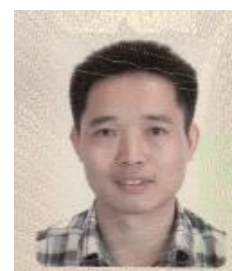

Xie Zhiqing is an advanced engineer at the Jiangsu Climate Center in China. He received her bachelor of science degree in agricultural application Meteorology from Nanjing Institute of Meteorology in 2000 and his master's degrees in meteorology from NUIST and graduated in 2003. He research interests are in extreme climate events, high temperature heat wave of urban agglomeration, atmospheric

environment and East Asian monsoon. He is the author of many high impact research articles and had received numerous awards of merit from local agencies. 